\title{
Current Directions in Deep Brain Stimulation for Parkinson's Disease-Directing Current to Maximize Clinical Benefit
}

\author{
Aristide Merola (D) - Alberto Romagnolo - Vibhor Krishna · Srivatsan Pallavaram • \\ Stephen Carcieri · Steven Goetz - George Mandybur · Andrew P. Duker · Brian Dalm • \\ John D. Rolston · Alfonso Fasano · Leo Verhagen
}

Received: January 6, 2020 / Published online: March 9, 2020

(C) The Author(s) 2020

\section{ABSTRACT}

Several single-center studies and one large multicenter clinical trial demonstrated that directional deep brain stimulation (DBS) could optimize the volume of tissue activated (VTA) based on the individual placement of the lead in relation to the target. The ability to generate axially asymmetric fields of stimulation translates into a broader therapeutic window (TW) compared to conventional DBS. However,

Aristide Merola and Alberto Romagnolo contributed equally to the manuscript and shared co-first authorship.

Enhanced digital features To view enhanced digital features for this article go to https://doi.org/10.6084/ m9.figshare.11864961.

Electronic supplementary material The online version of this article (https://doi.org/10.1007/s40120020-00181-9) contains supplementary material, which is available to authorized users.

A. Merola $(\bowtie)$

Department of Neurology, Ohio State University Wexner Medical Center, Columbus, OH, USA

e-mail: Aristide.Merola@osumc.edu

A. Romagnolo

Department of Neuroscience "Rita Levi Montalcini", University of Turin, Turin, Italy

V. Krishna · B. Dalm

Department of Neurosurgery, Ohio State Wexner

Medical Center, Columbus, OH, USA changing the shape and surface of stimulating electrodes (directional segmented vs. conventional ring-shaped) also demands a revision of the programming strategies employed for DBS programming. Model-based approaches have been used to predict the shape of the VTA, which can be visualized on standardized neuroimaging atlases or individual magnetic resonance imaging. While potentially useful for optimizing clinical care, these systems remain limited by factors such as patient-specific anatomical variability, postsurgical lead migrations, and inability to account for individual contact impedances and orientation of the systems of fibers surrounding the electrode. Alternative programming tools based on the functional assessment of stimulation-induced clinical benefits and side effects allow one to collect and analyze data from each electrode of the DBS system and provide an action plan of ranked alternatives for therapeutic settings based on the selection of optimal directional

\footnotetext{
S. Pallavaram

Neuromodulation Division, Abbott Laboratories, Austin, TX, USA

S. Carcieri

Boston Scientific Neuromodulation, Valencia, CA, USA

S. Goetz

Medtronic PLC Brain Modulation, Minneapolis, MN, USA
} 
contacts. Overall, an increasing amount of data supports the use of directional DBS. It is conceivable that the use of directionality may reduce the need for complex programming paradigms such as bipolar configurations, frequency or pulse width modulation, or interleaving. At a minimum, stimulation through directional electrodes can be considered as another tool to improve the benefit/side effect ratio. At a maximum, directionality may become the preferred way to program because of its larger TW and lower energy consumption.

Keywords: Contact; Deep brain stimulation; Directionality; Lead; Parkinson disease; Programming

\section{Key Summary Points}

Directional deep brain stimulation (DBS)

has the potential to minimize stimulation-induced side effects and maximize clinical benefits

To maximize the opportunity of directionality, the surgical planning should be based on the DBS lead level containing segmented directional electrodes

G. Mandybur

Mayfield Brain and Spine, Cincinnati, OH, USA

A. P. Duker

Department of Neurology, Gardner Family Center for Parkinson's Disease and Movement Disorders, University of Cincinnati, Cincinnati, OH, USA

J. D. Rolston

Department of Neurosurgery, University of Utah, Salt Lake City, UT, USA

\section{J. D. Rolston}

Department of Biomedical Engineering, University of Utah, Salt Lake City, UT, USA

\section{A. Fasano}

Edmond J. Safra Program in Parkinson's Disease, Morton and Gloria Shulman Movement Disorders Clinic, Toronto Western Hospital, UHN, Toronto, ON, Canada
Visualization software platforms can assist programming by estimating the volume of tissue activated by conventional or directional DBS electrodes

Functional software platforms can support directional programming by creating an action plan of ranked alternatives that may be needed over time

Directional DBS may avoid the need for complex stimulation protocols, such as bipolar stimulation, frequency or pulse width modulation, or interleaving

\section{INTRODUCTION}

Over the last three decades, the long-term efficacy of deep brain stimulation (DBS) in the management of Parkinson disease (PD) has been well established, with $60 \%$ improvement of levodopa-related motor complications [1, 2], $40-60 \%$ amelioration in quality of life [3], and a significant increase in quality-adjusted life expectancy [4]. Despite these remarkable results, not all patients experience maximal benefit from DBS. Unintentional spread of stimulation outside the target and into adjacent areas may result in dose-limiting motor or nonmotor side effects, preventing an optimal outcome $[5,6]$.

\section{A. Fasano}

Division of Neurology, University of Toronto, Toronto, ON, Canada

A. Fasano

Krembil Brain Institute, Toronto, ON, Canada

\section{A. Fasano}

CenteR for Advancing Neurotechnological Innovation to Application (CRANIA), Toronto, ON, Canada

L. Verhagen

Department of Neurological Sciences, Movement Disorder Section, Rush University, Chicago, IL, USA 
Directional leads represent an innovative technology designed to address this issue. The concept of steering current away from side effects and towards benefits after the lead is locked into place is appealing when considering the need to further improve the accuracy of DBS targeting [7]. Here, we discuss opportunities and challenges for directional DBS and review data in support of the integration of directional leads into clinical practice with regards to the functional anatomy of DBS target structures, planning strategies for optimal lead placement, and use of software platforms to assist the selection of the most promising stimulation settings. This article is based on previously conducted studies and does not contain any studies with human participants or animals performed by any of the authors.

\section{CLINICAL DATA SUPPORTING DIRECTIONALITY}

In 2014, two groups reported the results of intraoperative studies of directional DBS leads (not permanently implanted) (Table 1 ). In one study [8], the therapeutic window (TW), defined as the range between the minimal intensity of stimulation required to obtain meaningful clinical benefits, or therapeutic current strength (TCS), and the intensity of stimulation at which the first persistent side effect occurred, or side effect threshold (SET), was evaluated for single directional and omnidirectional configurations in 13 patients with PD or essential tremor (ET). The electrode used had two segmented contacts at the distal end, with three segments each, and two solid ring electrodes proximally. When test stimulation was performed, the TW was found to be $41.3 \%$ wider using the best directional electrode, compared to omnidirectional stimulation at that same level. The TCS was $43 \%$ lower for the best directional electrode compared to that required for omnidirectional stimulation, indicating a higher degree of efficiency with directional DBS. In the second study [9], eight patients with PD were assessed intraoperatively using an experimental lead with 32 oval disc-shaped thin-film electrode contacts arranged on eight rows of four contacts. The patient, the evaluating neurologist, and the neurosurgeon were blind to the direction of the steering modes. When compared to omnidirectional stimulation, directional DBS increased the TW in all patients, with a gain ranging from 0.5 to $1.5 \mathrm{~mA}$. In seven out of eight cases, SETs could be increased by at least $1 \mathrm{~mA}$ when using directional DBS.

Three single-center studies investigated US Food and Drug Administration (FDA)-approved directional implants (Table 1) employing a "1-33-1" lead design with the two central rows segmented into three individually controlled electrodes; each segment spaced $120^{\circ}$ apart in the plane orthogonal to the long axis of the lead. These studies found that best directional DBS has a significantly larger median TW and higher SET $[10,11]$, as well as slightly lower total electrical energy delivered (TEED) [12]. More recently, a large international, multicenter, prospective, crossover study of 234 patients with PD undergoing subthalamic nucleus (STN) DBS from 37 centers across seven countries (the PROGRESS Study, Abbott St. Jude Medical, Plano, TX, USA) confirmed the superiority of directional vs. omnidirectional programming [13]. In this study, patients were conventionally (i.e., non-directionally) stimulated for 3 months at the optimal ring. At the 3-month primary endpoint, the optimal ring settings were confirmed and in the same session the best directional settings were identified between the three individual segments and the three pairwise combinations of segments at the best segmented level. The best ring and best directional montages were then evaluated in a randomized (based on a coin toss) and double-blinded (patient and the clinician) fashion and their TWs were recorded. Study details and results of the primary endpoint are included in Table 2. All patients had 12 months of follow-up and several measures were tracked in this period at 3, 6, and 12 months including Unified PD Rating Scale (UPDRS)-III (motor section), UPDRS-II (activities of daily living section), clinician preference, patient preference, 39-item PD Questionnaire (PDQ-39), adverse events, and others. 
Table 1 Data from single-center studies on directional DBS

\begin{tabular}{|c|c|c|c|c|c|c|}
\hline $\begin{array}{l}\text { Author and } \\
\text { year }\end{array}$ & $\begin{array}{l}\text { Sample } \\
\text { size }\end{array}$ & $\begin{array}{l}\text { Lead } \\
\text { configuration }\end{array}$ & $\begin{array}{l}\text { Clinical } \\
\text { setting }\end{array}$ & Efficacy measures & FUP & Main results \\
\hline $\begin{array}{l}\text { Pollo et al. } \\
2014 \text { [8] }\end{array}$ & $\begin{array}{l}11 \mathrm{PD} \\
(\mathrm{STN}) \\
2 \mathrm{ET} \\
(\mathrm{Vim})\end{array}$ & $\begin{array}{l}2 \text { distal } \\
\text { segmented } \\
\text { contacts ( } 3 \\
\text { segments } \\
\text { each) } \\
2 \text { proximal } \\
\text { ring } \\
\text { contacts }\end{array}$ & $\begin{array}{l}\text { Intraoperative } \\
\text { double- } \\
\text { blinded } \\
\text { evaluation }\end{array}$ & $\begin{array}{l}\text { Full effect on rigidity } \\
\text { or good effect on } \\
\text { tremor }\end{array}$ & NA & $\begin{array}{l}\text { TW } 41.3 \% \text { wider and } \\
\text { TCS } 43 \% \text { lower with } \\
\text { directional vs. } \\
\text { omnidirectional } \\
\text { stimulation }\end{array}$ \\
\hline $\begin{array}{l}\text { Contarino } \\
\text { et al. } \\
2014 \text { [9] }\end{array}$ & $\begin{array}{l}8 \text { PD } \\
\quad(\mathrm{STN})\end{array}$ & $\begin{array}{l}32 \text { oval disc- } \\
\text { shaped } \\
\text { contacts }\end{array}$ & $\begin{array}{l}\text { Intraoperative } \\
\text { double- } \\
\text { blinded } \\
\text { evaluation }\end{array}$ & Full effect on rigidity & $\mathrm{NA}$ & $\begin{array}{l}\text { TW wider } \\
(0.5-1.5 \mathrm{~mA}) \text { with } \\
\text { directional vs. } \\
\text { omnidirectional } \\
\text { stimulation }\end{array}$ \\
\hline $\begin{array}{l}\text { Steigerwald } \\
\text { et al. } \\
2016[10]\end{array}$ & $\begin{array}{l}7 \text { PD } \\
(\mathrm{STN})\end{array}$ & $\begin{array}{l}2 \text { central } \\
\text { segmented } \\
\text { contacts (3 } \\
\text { segments } \\
\text { each) } \\
1 \text { proximal } \\
\text { and } 1 \text { distal } \\
\text { ring } \\
\text { contacts }\end{array}$ & $\begin{array}{l}\text { Retrospective } \\
\text { unblinded } \\
\text { analysis of } \\
\text { permanently } \\
\text { implanted } \\
\text { patients }\end{array}$ & Full effect on rigidity & $3-6$ months & $\begin{array}{l}\text { TW variations from } \\
-100 \% \text { to }+440 \% \\
\text { with directional vs. } \\
\text { omnidirectional } \\
\text { stimulation } \\
\text { Best TW improvement } \\
\text { with the best } \\
\text { directional contact at } \\
\text { the less effective level } \\
\text { At 3-6 months, all } \\
\text { patients remained in } \\
\text { directional } \\
\text { stimulation }\end{array}$ \\
\hline
\end{tabular}


Table 1 continued

\begin{tabular}{|c|c|c|c|c|c|c|}
\hline $\begin{array}{l}\text { Author and } \\
\text { year }\end{array}$ & $\begin{array}{l}\text { Sample } \\
\text { size }\end{array}$ & $\begin{array}{l}\text { Lead } \\
\text { configuration }\end{array}$ & $\begin{array}{l}\text { Clinical } \\
\text { setting }\end{array}$ & Efficacy measures & FUP & Main results \\
\hline $\begin{array}{l}\text { Dembek } \\
\text { et al. } \\
2017 \text { [11] }\end{array}$ & $\begin{array}{l}10 \mathrm{PD} \\
(\mathrm{STN})\end{array}$ & $\begin{array}{l}2 \text { central } \\
\text { segmented } \\
\text { contacts (3 } \\
\text { segments } \\
\text { each) } \\
1 \text { proximal } \\
\text { and } 1 \text { distal } \\
\text { ring } \\
\text { contacts }\end{array}$ & $\begin{array}{c}\text { Prospective } \\
\text { double- } \\
\text { blinded }\end{array}$ & $\begin{array}{l}\text { Improvement of at } \\
\text { least } 1.5 \text { points in } \\
\text { the UPDRS-III } \\
\text { composite scores of } \\
\text { upper limb rigidity, } \\
\text { finger tapping, and } \\
\text { hand rotation }\end{array}$ & 3-6 months & $\begin{array}{l}\text { TW wider with } \\
\text { directional vs. } \\
\text { omnidirectional } \\
\text { stimulation (median } \\
2 \mathrm{~mA} \text { vs } 1 \mathrm{~mA} \text { ) } \\
\text { SET higher with } \\
\text { directional vs. } \\
\text { omnidirectional } \\
\text { stimulation (median } \\
4 \mathrm{~mA} \text { vs } 3 \mathrm{~mA} \text { ) } \\
\text { At } 3-6 \text { months, } 14 \\
\text { leads remained in } \\
\text { directional } \\
\text { stimulation }\end{array}$ \\
\hline $\begin{array}{r}\text { Rebelo et al. } \\
2018 \text { [12] }\end{array}$ & $\begin{array}{c}3 \mathrm{PD} \\
(\text { Vim }) \\
3 \mathrm{DT} \\
(\text { Vim) } \\
2 \mathrm{ET} \\
(\text { Vim })\end{array}$ & $\begin{array}{l}2 \text { central } \\
\text { segmented } \\
\text { contacts (3 } \\
\text { segments } \\
\text { each) } \\
1 \text { proximal } \\
\text { and } 1 \text { distal } \\
\text { ring } \\
\text { contacts }\end{array}$ & $\begin{array}{l}\text { Retrospective } \\
\text { unblinded } \\
\text { analysis of } \\
\text { permanently } \\
\text { implanted } \\
\text { patients }\end{array}$ & Full effect on tremor & 6 months & $\begin{array}{l}\text { TW wider (1.86 mA } \\
\text { vs. } 0.97 \mathrm{~mA}) \text { and } \\
\text { TCS lower }(1.51 \mathrm{~mA} \\
\text { vs. } 2.19 \mathrm{~mA}) \text { with } \\
\text { directional vs. } \\
\text { omnidirectional } \\
\text { stimulation } \\
\text { TEED 6-18\% lower } \\
\text { with directional vs. } \\
\text { omnidirectional } \\
\text { stimulation } \\
\text { At } 6 \text { months, } 9 \text { leads } \\
\text { remained in } \\
\text { directional } \\
\text { stimulation }\end{array}$ \\
\hline
\end{tabular}

$D T$ dystonic tremor, ET essential tremor, FUP follow-up, PD Parkinson disease, $N A$ not applicable, $S E T$ side effects threshold, STN subthalamic nucleus, TCS therapeutic current strength, TEED total electrical energy delivered, $T W$ therapeutic window, UPDRS Unified PD Rating Scale, Vim ventral intermediate nucleus 
Table 2 Data from the PROGRESS study

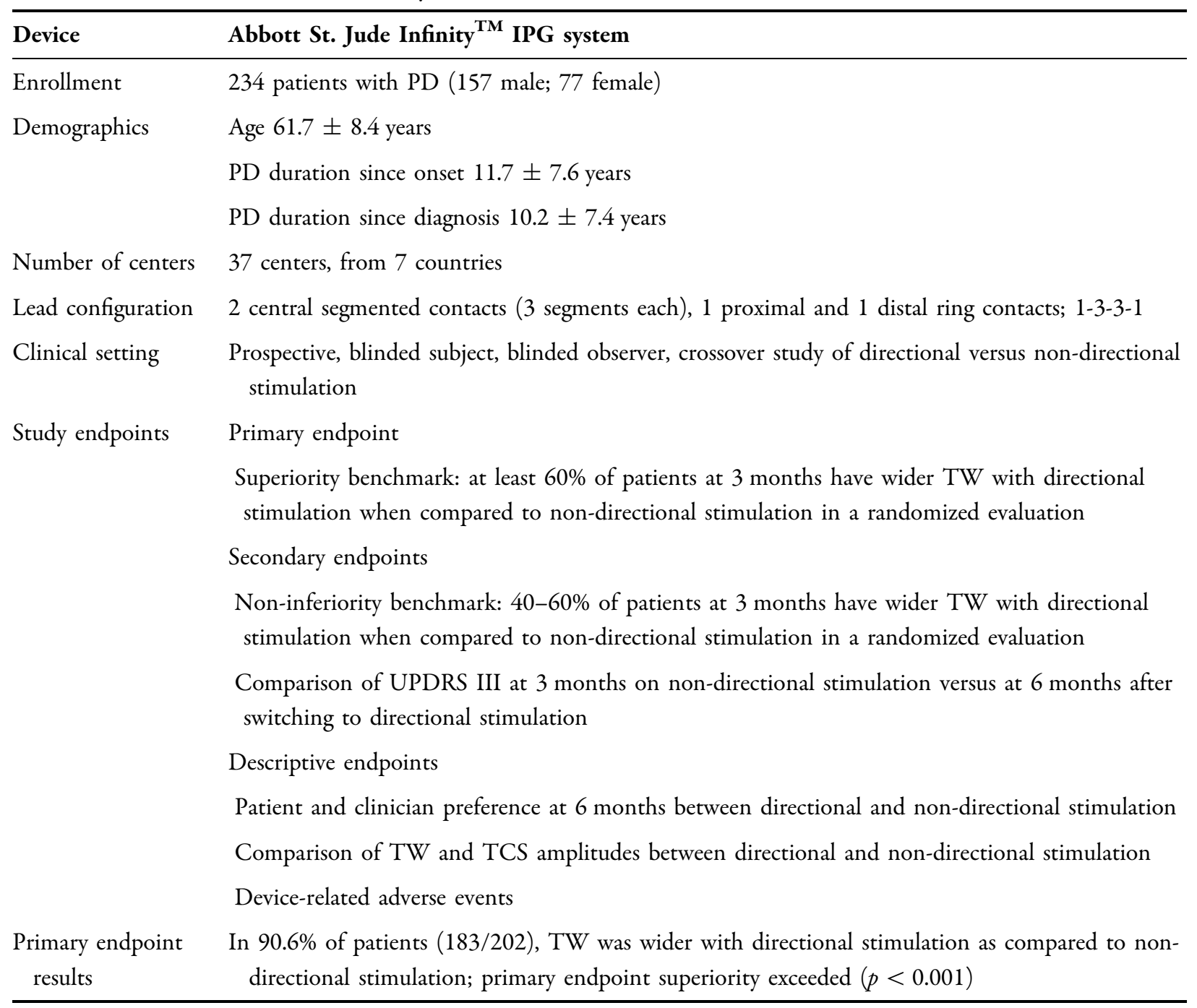

$D B S$ deep brain stimulation, $P D$ Parkinson disease, $T C S$ therapeutic current strength, $T W$ therapeutic window

\section{CHALLENGES ASSOCIATED WITH DIRECTIONAL PROGRAMMING}

While directional DBS systems allow fine control over the parameters by which they deliver stimulation, including location, size, shape, and nature of neural activation, this increased ability to provide accurate and personalized stimulation demands a revision of paradigms currently used for the placement and programming of DBS electrodes. In particular, the anatomical and functional connections of the
DBS targets, as well as the bioelectrical properties of directional vs. conventional leads, represent critical aspects to be considered for the development of innovative DBS protocols.

\section{DBS Target Structures: Anatomical and Functional Connections}

The STN is a small lens-shaped structure located in the anterior-lateral portion of the midbrain at the junction of the cerebral peduncle to the tegmentum (Fig. 1). Leads are generally implanted following an oblique trajectory from 


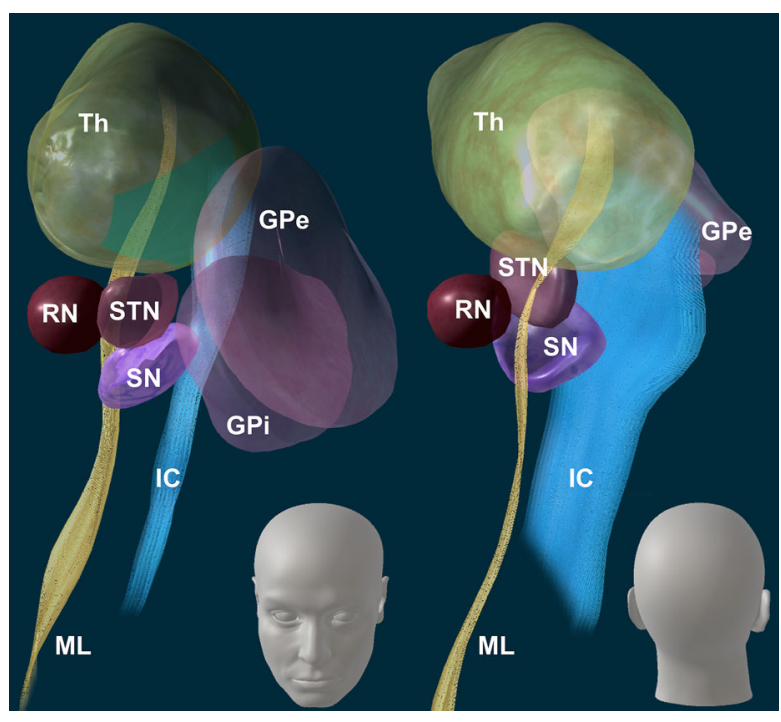

Fig. 1 DBS target structures. Anatomical DBS structures of the left hemisphere in the anterior (left) and posterior (right) views. Courtesy of Abbott's anatomical visualization educational software (StimDirect), available on the St. Jude Infinity ${ }^{\mathrm{TM}}$ clinician programmer. Subthalamic nucleus (STN): ventrally, the STN is bordered by the substantia nigra $(\mathrm{SN})$, anterolaterally by the internal capsule (IC), posteriorly by the medial lemniscus (ML), dorsally by the zona incerta and the fields of Forel, and medially by the red nucleus ( $\mathrm{RN}$ ), the medial forebrain bundle, and the midbrain course of the oculomotor nerve. Globus pallidus pars interna (GPi): ventrally, the GPi is bordered by the ansa lenticularis, which separates it from the nucleus basalis and the amygdala, ventromedially by the optic tract, dorsally and medially by the posterior limb of the internal capsule, and laterally by the internal medullary lamina of the globus pallidus which separates it from the globus pallidus pars externa (GPe). Additionally, the GPi is divided into an internal and external component by the incomplete medullary lamina of the globus pallidus. Th thalamus

a dorsal lateral entry point to a more ventral medial endpoint in the STN. Given the high number of important surrounding structures, stimulation-induced side effects are important to recognize and, if seen, can guide inferences about the location of the lead in relation to the planned STN target (Table 3). Functionally, the STN has a complex microanatomy, with large dendritic trees that are synaptically convergent between afferents from different functional areas [14-16] (Table 4).
The globus pallidus pars interna (GPi) is a triangular-shaped structure forming the inner part of the lentiform nucleus of the basal ganglia (Fig. 1). DBS leads are generally implanted following a parasagittal trajectory that traverses putamen, globus pallidus pars externa (GPe), and GPi. The target is in the posterolateral part of GPi, just medial to the medullary lamina that separates GPe and GPi and the tip of the electrode will be just dorsolateral to the optic tract. Stimulation-induced side effects, when present, can guide inferences about the location of the lead in relation to the planned target (Table 3). Functionally, the GPi is a site of convergence of striatal-pallidal efferents [17-28]. Together with the substantia nigra pars reticulata ( $\mathrm{SNr}$ ), GPi represents the main basal ganglia output to the ventroanterior and ventrolateral thalamic nuclei and, eventually, to the cortex [29] (Table 4).

\section{Surgical Approach and Considerations Related to Type of DBS Lead}

In currently used planning strategies, the STN may be targeted at the anterior border of the red nucleus, $2 \mathrm{~mm}$ lateral to its medial border, and at $4 \mathrm{~mm}$ inferior to the anterior commissure-posterior commissure (AC-PC) plane [30]. GPi may be targeted $3 \mathrm{~mm}$ lateral to its medial border and one-third of its length anterior from its posterior margin, all at the AC-PC plane [30]. However, these heuristics are not absolute, and other effective targeting strategies may also be applied. In addition, the precise targets within these areas are still contested by experts [31, 32]. In particular, the optimal spot for stimulation within the STN remains debated [33].

For directional leads, targeting currently remains the same as for legacy quadripolar leads. However, more attention must be paid to the depth of the electrodes. Most manufacturers (Boston Scientific and Abbott) have directional capabilities only in their second and third contact rows, not in the first or fourth. The Aleva directSTN Acute lead, on the other hand, has directional first and second rows only, which better suit GPi because of the proximity to the internal capsule at the bottom of the lead 
Table 3 Stimulation-induced side effects

\begin{tabular}{|c|c|c|c|}
\hline & Direction of current spread & Side effect & Structures involved \\
\hline \multirow[t]{14}{*}{ STN } & Lateral or anterolateral & Contralateral muscle contractions & Internal capsule \\
\hline & & Facial or tongue pulling & \\
\hline & & Dysarthria & \\
\hline & & Eyelid opening apraxia & \\
\hline & & Contralateral gaze deviation & \\
\hline & Anteromedial & $\begin{array}{l}\text { Autonomic changes/vegetative side effects } \\
\text { (nausea, heat sensation, sweating) }\end{array}$ & Lateral hypothalamic area \\
\hline & Medioventral & Disconjugate gaze & Oculomotor nerve \\
\hline & & Diplopia & \\
\hline & Posterior & Paresthesias & Medial lemniscus \\
\hline & Dorsal or ventral & Bradykinesia worsening $^{a}$ & Zona incerta/thalamus \\
\hline & & Levodopa effect reduction & Substantia nigra \\
\hline & & Mood changes (mania, depression, or apathy) & \\
\hline & Scarcely localizable & Impulsivity & - \\
\hline & & Hypophonia & \\
\hline \multirow[t]{6}{*}{ GPi } & Medial & Contralateral muscle contractions & Internal capsule \\
\hline & Posterior & Bradykinesia worsening $^{\mathrm{a}}$ & \\
\hline & Dorsal & Dyskinesia & Globus pallidus pars externa \\
\hline & Ventral & Phosphenes & Optic tract \\
\hline & Lateral & No side effects & Globus pallidus pars externa \\
\hline & Anterior & & \\
\hline
\end{tabular}

$G P i$ globus pallidus pars interna, $S T N$ subthalamic nucleus

${ }^{a}$ In spite of rigidity improvement

[34]. With currently available electrodes, the depth of the electrode should be targeted with the intention of using a directional row (typically the second or third) as the active contact. Depending on the surgeon's practice, this might require inserting the electrode deeper than with a standard quadripolar lead.

To help ensure consistent orientation of the segments of the directional lead, manufacturers have placed a fiducial on the lead proximal to the four electrode levels. When the fiducial points in the anterior direction, the three segments face anteriorly, posteromedially, and posterolaterally, respectively. Nevertheless, during implantation, the lead is subject to torsional movements, making it difficult to predict the exact position of the fiducial marker and, therefore, the exact orientation of each segment. If there is uncertainty regarding the directionality, high-resolution X-rays, fluoroscopy, or CT scan can be used to verify the rotational orientation [35].

\section{DIRECTIONAL PROGRAMMING}

The main goal of the first programming visit is to determine the TW for each of the electrode 
Table 4 STN and GPi functional connections

\begin{tabular}{|c|c|c|c|c|c|}
\hline & \multicolumn{3}{|l|}{ Input } & \multicolumn{2}{|l|}{ Output } \\
\hline & Afferents & $\begin{array}{ll}\text { Neurotransmitter } & \text { i }\end{array}$ & $\begin{array}{l}\text { STN area } \\
\text { involved }\end{array}$ & Efferents & Neurotransmitter \\
\hline \multirow[t]{6}{*}{ STN } & Globus pallidus pars externa & GABA & $\begin{array}{l}\text { Dorsolateral } \\
\quad \text { (motor area) } \\
\text { Ventromedial } \\
\text { (limbic area) }\end{array}$ & $\begin{array}{l}\text { Globus pallidus } \\
\text { pars interna }\end{array}$ & Glutamate \\
\hline & $\begin{array}{l}\text { Primary motor cortex } \\
\text { Supplementary motor area } \\
\text { Premotor cortex }\end{array}$ & Glutamate & $\begin{array}{l}\text { Dorsolateral } \\
\text { (motor area) }\end{array}$ & $\begin{array}{r}\text { Substantia nigra } \\
\text { pars reticulata }\end{array}$ & Glutamate \\
\hline & $\begin{array}{l}\text { Prefrontal cortex } \\
\text { Prelimbic-medial orbital areas }\end{array}$ & Glutamate & $\begin{array}{l}\text { Ventromedial } \\
\text { (limbic area) }\end{array}$ & - & - \\
\hline & $\begin{array}{l}\text { Thalamus (parafascicular and } \\
\text { centromedian nuclei) }\end{array}$ & Glutamate & $\begin{array}{l}\text { Dorsolateral } \\
\quad \text { (motor area) } \\
\text { Ventromedial } \\
\text { (limbic area) }\end{array}$ & - & - \\
\hline & Input & & Output & & \\
\hline & Afferent area & Neurotransmitter & Efferent a & & Neurotransmitter \\
\hline \multirow[t]{7}{*}{ GPi } & Striatum (putamen and caudate) & GABA & $\begin{array}{l}\text { Thalamus } \\
\text { ventrolat }\end{array}$ & $\begin{array}{l}\text { entroanterior and } \\
\text { al nuclei) }\end{array}$ & GABA \\
\hline & Globus pallidus pars externa & GABA & Substantia & igra pars compacta & GABA \\
\hline & Thalamus (intralaminar nucleus) & Glutamate & Lateral hab & nular nucleus & GABA \\
\hline & STN & Glutamate & Pedunculo & ntine nucleus & GABA \\
\hline & Pedunculopontine nucleus & $\begin{array}{l}\text { Glutamate and } \\
\text { acetylcholine }\end{array}$ & - & & - \\
\hline & Dorsal raphe nucleus & Serotonin & - & & - \\
\hline & Substantia nigra & Dopamine & - & & - \\
\hline
\end{tabular}

GABA gamma-aminobutyric acid, GPi globus pallidus pars interna, $S T N$ subthalamic nucleus

contacts [36]. Directional leads are often first tested in ring mode, followed by directional stimulation on individual segments if efficacy in ring mode is limited by stimulation-related side effects, or to identify programming strategies that allow a larger TW with lower energy consumption [37]. Supporting programming software allows for visualizations of the anatomical context along with the predicted volume of tissue activated (VTA) and for functional mapping of the thresholds for clinical efficacy and side effects. Some of these tools also allow for an integrated analysis of power consumption adjusted to each contact impedance. 


\section{Visualization of Volume of Tissue Activated}

The volume of neural activation can be estimated using finite element techniques, wherein a computer system subdivides a volumetric region of interest and solves for a scenario by applying appropriate mathematical relationships, initial conditions, and boundary conditions and iterating until a stable solution results. In this domain, this is applied by positioning an appropriate model of a stimulating electrode, configuring it with appropriate stimulation parameters (polarities, stimulus amplitude), and determining the resulting current flows and voltage gradients in the surrounding tissue. These electromagnetic gradients can then be applied, in a second step, to a population of simulated neurons positioned and oriented preferentially around the stimulating electrode so as to determine points at which neurons may be activated by a given stimulation regime [38]. These neurons may be modeled such that they respond both to the intensity of the stimulation (current amplitude) and the time-dependent parameters such as the width of a stimulation pulse [38]. As an example, various neuron fiber diameters may be included, such that the response of smaller fibers to a given stimulus pulse is different than that of larger fibers. The resulting neuron population that is predicted to be activated can then be represented visually, as a volume enclosing the points of activation.

Model-based approaches have been shown to have some predictive value when used in visual programming systems [39]. However, validating these models can be challenging, as it is difficult to know with certainty which neural tissue volumes are indeed activated by stimulation. One thing that has been established is that fully featured models incorporating voltage drop and capacitance of the electrode-electrolyte interface, tissue encapsulation of the electrode, and diffusion tensor-based 3D tissue anisotropy and inhomogeneity produce more realistic predictions than simpler models that do not account for these factors [40].

As new stimulation modalities are introduced, including the new options afforded by directional leads, these VTA models may be used to compare the different stimulation options available. As examples, in bipolar stimulation, they can be used to understand the differences in volume between anodal and cathodal activation regions. For interleaved stimulation, they can be used to understand areas of overlap in separate pulse trains, wherein tissue receives stimulation at double the underlying frequency [41]. In directional stimulation, the ability to push stimulation off axis, commonly referred to as displacement of the VTA centroid, can be explored in comparison to traditional ring mode stimulation. This may be of specific interest, as the thresholds to activation in directional stimulation may be different than in traditional rings. For fixed stimulation amplitudes, the smaller surface area of a directional segment creates relatively higher gradients around the electrode which may increase the probability of neural activation [38].

\section{Visualization Strategies: Opportunities}

\section{Patient-Specific Anatomy}

A preoperative magnetic resonance imaging (MRI) may be used to establish the location and boundaries of anatomical structures, either through adaptation of an anatomical atlas or direct segmentation of structure boundaries from intensity information in the images themselves. Further, fiber tracts may additionally be represented if appropriate imaging sequences (diffusion tensor imaging) or atlases are available.

\section{Final Lead Location and Orientation}

A postoperative, or in some cases an intraoperative, image may be used to establish the final lead location and orientation. For this purpose, images that clearly delineate the electrode positions and the orientation of fiducial markers included in the lead body via a hyper- or hypo-intense image artifact can be used.

Visualization of Predicted Stimulation Extent A VTA or similar model may be applied to the representation of the stimulating electrodes. Models may be created for one or more 
potential sets of stimulating parameters (i.e., different active contacts, different current or voltage amplitudes, monopolar vs. bipolar stimulation, directional vs. conventional ring stimulation, etc.) such that the overlap of the resulting stimulation field to patient anatomy can be assessed.

\section{Integration of Ancillary Information}

In addition to anatomy, lead location, and stimulation extent, visualization solutions may additionally allow for the addition of other information of potential use in identifying optimal stimulation settings. For example, intra- or postoperative electrophysiological measures may be visualized in the patientspecific anatomical context. In addition, aggregated historical information about stimulation outcome in the form of a statistical outcome or side effect map may be visualized in the patientspecific anatomical context to further inform programming decisions.

\section{Visualization Strategies: Challenges}

\section{Limitations of Anatomical Models}

Currently used anatomical models on which the lead is visualized are usually not patientspecific, and even when patient-specific, they are based on presurgical MRI images that do not account for procedural brain shift and postsurgical anatomical changes reported at up to $4 \mathrm{~mm}$ in the deep brain [42-46].

\section{Deviation of DBS Lead}

DBS leads show large deviations from their intended implanted orientation: more than $30^{\circ}$ rotation in $42 \%$ of the leads and more than $60^{\circ}$ rotation in $11 \%$ of the leads [47]. Thus, the orientation of the individual segmented contacts might be no longer valid relative to the underlying anatomy in presurgical MRI presented during programming. Furthermore, significant lead migration (greater than $3 \mathrm{~mm}$ ) along the ventrodorsal axis or upward displacement from immediate to delayed CT has been reported in over $12 \%$ of leads placed at an expert center [48, 49].

\section{Variability in Tissue Impedance and Anisotropy}

Validating VTA models is challenging as it is difficult to know with certainty which neural tissue volumes are stimulated [50]. VTA models made available for programming are based on generic homogeneous models that do not account for tissue inhomogeneities, for instance permittivity and conductivity of brain structures, which may alter VTA predictions from - $44 \%$ to $174 \%$ [51]. Also, VTA models available in programming platforms do not account for patient-specific tissue anisotropy that can at best only be modeled using tractography from high-resolution patient-specific diffusion tensor imaging (DTI) [52, 53]. Other real-world factors, not usually modeled, that influence the accuracy, shape, and extent of the VTA include physiology and pathophysiology [50], brain pulsation and patient hydration [54], glial scar formation around the electrode [55], and local fluid retention [56].

\section{Software Platforms to Assist DBS Programming}

SureTune $^{\mathrm{TM}}$ (Supplementary Fig. S1) is a programming visualization tool available for clinical use in many regions and close to being released also in the USA. It incorporates the Bardinet-Yelnick anatomic atlas and registration algorithm [57], and further allows a user to manually adjust structure size, shape, and location to allow for valid representation of a patient's specific anatomical variation. It also supports intensity-based segmentation of MRI visible structures. Within the existing software, leads can be placed according to stereotactic coordinates or aligned via postoperative images. Anatomic representations of structures can be validated by co-registration of microelectrode recordings to confirm anatomical boundaries if additional confidence is desired. Stimulation modeling is available for common stimulation configurations, and stimulation plans can be created for use in the clinical setting. Finally, via a service offering, statistical maps of outcome or side effects can be created which can then be prospectively visualized to inform future 
clinical decision-making or research applications: a recent study [58] showed that such statistical maps correlated well with best clinical programming, demonstrating predictive utility in prospective cohorts for GPi stimulation in dystonia.

While potentially useful for optimizing clinical care, SureTune ${ }^{\mathrm{TM}}$ has several limitations. Its atlas is a single brain histologically based example that may not account for subject to subject variation in anatomy. While its approach of algorithmic fitting plus human adjustment can be highly accurate, it is also dependent on image quality and human judgment to achieve a good patient-specific fit. Finally, it uses homogeneous and isotropic assumptions in its VTA methodology, which may introduce errors in the visualization due to variation of tissue properties within a specific patient's brain.

SureTune $^{\mathrm{TM}}$ is tightly integrated with other Medtronic surgical tools, allowing import of surgical information from Stealth ${ }^{\mathrm{TM}}$ navigation and planning software and the documentation of intraoperative electrophysiology which may further validate a patient-specific visualization. Medtronic's current programming offering allows visualization of the VTA created by the device and the annotation of clinical observations. Future updates to SureTune ${ }^{\mathrm{TM}}$ will extend interoperability, allowing anatomical and electrophysiological information to appear on the programming tablet along with the stimulation volumes.

\section{Boston Scientific GUIDE ${ }^{T M} X T$}

The Boston Scientific neuromodulation stimulators use a system that includes both VTA modeling and functional testing. Visualization of VTAs with the Boston Scientific system is available through a software tool (GUIDE $^{\mathrm{TM}}$ $\mathrm{XT}$ ). GUIDE $^{\mathrm{TM}} \mathrm{XT}$ is compatible with the BrainLab Elements (Munich, Germany) surgical planning software, available for clinical use in many countries. The software enables 3D modeling and visualization of the VTA relative to the patient's anatomical structures. To generate a model of lead location in the brain, a simulated DBS lead from a patient's postoperative CT scan is registered to an anatomical atlas based on segmentation of a patient's preoperative MRI. Clinical stimulation parameters can then be programmed onto the simulated lead to generate the associated VTA. In cases of suboptimal electrode placement or clinical response, additional options may be needed, and current steering between directional segments may be useful to expand the TW (Supplementary Fig. S2) [10]. Visualization tools may be useful for understanding these nuances of directional DBS and adjusting stimulation appropriately. For example, the VTA created by coactivation of two segments has a different shape than the VTA created by activation of a single segment, with the former having a lesser radial extent of activation than the latter at the same amplitudes. The Vercise ${ }^{\mathrm{TM}}$ system also includes the Neural Navigator software, intended to aid in functional testing of different stimulator settings by mapping the resulting clinical effects. Therapeutic effects and side effects associated with monopolar stimulation on both ring and directional electrodes are represented on a 2D clinical effects map (Supplementary Figs. S3 and S4), and effects may be recorded on all leads for all stimulation configurations. VTAs for both standard DBS leads and directional DBS leads are also visualized within the Neural Navigator software, which can import the anatomical structures from the BrainLab platform.

\section{Abbott Informity ${ }^{T M}$}

While the Abbott Infinity ${ }^{\mathrm{TM}}$ clinician programmer does not have a VTA visualization tool, it includes the Informity ${ }^{\mathrm{TM}}$ programming software designed primarily for simplifying functional programming. The software guides the user through directional programming using visual representations of stimulation responses, occurrences of stimulation-induced symptom relief and side effects, to create an action plan of ranked electrode montage alternatives that may be needed over time during therapy. The layout and workflow of the Informity ${ }^{\mathrm{TM}}$ programming software enable "event markers" to document the amplitudes that produce symptom relief and side effects (Supplementary Figs. S5, S6, and S7). After monopolar survey of ring and segmented electrodes, the Informity ${ }^{\mathrm{TM}}$ software allows clinicians to rank the investigated 
montages according to various clinically relevant criteria. With traditional omnidirectional programming, amongst montages with comparable outcomes some clinicians prioritize maximizing the TW while others prioritize minimizing the TCS (power consumption). To that end, the decision support tool available within the Informity $^{\mathrm{TM}}$ software not only allows ranking the montages on the basis of power (microwatts) and TW (milliamps) but also on the basis of a measure referred to as the therapeutic window percentage (TW\%). TW\%, which is TW expressed as a percentage of TCS, is a means to balance the trade-off between maximizing TW and minimizing TCS and gives clinicians a means to optimize gains in both TCS and TW simultaneously. A final sorting option, balanced threshold, gives clinicians an additional level of optimization to balance gains in TW\% while minimizing power consumption as per clinician preference (Supplementary Fig. S7). The software allows complete customization of symptom relief and side effect lists and enables the export of the entire functional programming session in the form of a PDF report that can be exported to electronic medical records for future review.

\section{CONCLUSIONS}

Increasing clinical evidence supports the superiority of directional over omnidirectional stimulation. It is conceivable that directional leads, by providing asymmetric stimulation, may avoid the need for complex programming paradigms such as bipolar stimulation, frequency or pulse width modulation, or interleaving. At a minimum, stimulation through directional electrodes can be considered as another tool to improve the benefit/side effect ratio. At a maximum, directional stimulation may become the preferred way to program, even when omnidirectional stimulation causes no side effects, because of its larger TW and lower energy consumption.

However, as new DBS systems increase in their capability to control the shape, size, and location of stimulated neural tissue, the complexity of optimizing the configuration of such systems grows as well. The use of simple programming protocols, such as the activation of a single directional segment, has proved to be effective in the vast majority of cases [13]. Directional multiple-electrode programming configurations, whether using independent current controllers or interleaving, may provide additional nuances in programming strategies, but may also result in increased programming complexity [59], changes to battery power consumption, and reduction in the laterality of the volume of activation [60]. To assist with DBS programming, DBS producers developed innovative software platforms for functional mapping, as well as tools for visualization of the volume of neural activation. Still, these models are constrained by simplifying assumptions, such as using homogeneous and isotropic tissue environments and arbitrarily positioned populations of generally linear axons. Also, no study has so far established if commercially available software platforms are superior to standard programming.

In conclusion, while directionality offers a unique opportunity to improve the functional outcomes of DBS, it also requires definition of unified strategies for functional mapping and common standards for VTA visualization since suboptimal programming remains one of the major causes for DBS failure $[6,61]$. Here, we advocate for intensive collaboration between DBS manufacturers and academic centers to develop and test in large multicenter clinical trials innovative programming algorithms aiming at maximizing the benefits of directional DBS.

\section{ACKNOWLEDGEMENTS}

Funding. No funding or sponsorship was received for this study or publication of this article.

Authorship. All named authors (Dr. Merola, Dr. Romagnolo, Dr. Krishna, Dr. Pallavaram, Dr. Carcieri, Dr. Goetz, Dr. Mandybur, Dr. Duker, Dr. Dalm, Dr. Rolston, Dr. Fasano, and Dr. Verhagen Metman) meet the International 
Committee of Medical Journal Editors (ICMJE) criteria for authorship for this article, take responsibility for the integrity of the work as a whole, and have given their approval for this version to be published.

Disclosures. Aristide Merola is supported by NIH (KL2 TR001426) and has received speaker honoraria from CSL Behring, Abbvie, and Cynapsus Therapeutics. He has received Grant support from Lundbeck. Alberto Romagnolo has received Grant support and speaker honoraria from AbbVie, speaker honoraria from Chiesi Farmaceutici and travel Grants from Lusofarmaco, Chiesi Farmaceutici, Medtronic, and UCB Pharma. Vibhor Krishna has received research Grant from Medtronic, Boston Scientific, and Abbott. Srivatsan Pallavaram is a Medical Science Advisor (Medical Affairs) at Abbott Labs and receives salary for his services. Stephen Carcieri is an employee at Boston Scientific and receives salary for his services. Steven Goetz is an employee at Medtronic and receives salary for his services. George Mandybur has received consulting agreement with Boston Scientific and Abbott, as well as research Grants from Boston Scientific. Andrew P. Duker and Brian Dalm have nothing to declare. John D. Rolston has consulting agreements with NeuroPace and Medtronic, and stock in Axion Biosystems. He received funding from the NIH (NCATS KL2 TR002539 and NINDS K23 NS114178). Alfonso Fasano sits in the advisory board of Evotion, Inbrain Neuroelectronics and Cortics, received honoraria for consultancies from Apple, Abbvie, Abbott, BrainLab, Boston Scientific, Chiesi farmaceutici, Ipsen, Medtronic, Sunovion, and UCB; honoraria for participation in advisory boards from Abbvie, Boston Scientific, and Ipsen; research Grants from Abbvie, Boston Scientific, Cummings Foundation, Dystonia Medical Research Foundation Canada, Michael J. Fox Foundation, Medtronic, and University of Toronto. Leo Verhagen sits in the advisory boards of Abbott Neuromodulation, AbbVie Inc, Biogen Inc. He is in the editorial board of Neurology and Therapy and Brain Sciences. He has received consultancies from Abbott, AbbVie Inc, and Boston Scientific, and research support from Medtronic, Boston Scientific, Abbott,
AbbVie, Neuroderm, Biogen Inc, and Prilenia therapeutics. He has received NIH funding (R01 NS40902) as a site-PI. Leo Verhagen is a member of the journal's Editorial Board.

Compliance with Ethics Guidelines. This article is based on previously conducted studies and does not contain any studies with human participants or animals performed by any of the authors.

Data availability. Data sharing is not applicable to this article as no datasets were generated or analyzed during the current study.

Open Access. This article is licensed under a Creative Commons Attribution-NonCommercial 4.0 International License, which permits any non-commercial use, sharing, adaptation, distribution and reproduction in any medium or format, as long as you give appropriate credit to the original author(s) and the source, provide a link to the Creative Commons licence, and indicate if changes were made. The images or other third party material in this article are included in the article's Creative Commons licence, unless indicated otherwise in a credit line to the material. If material is not included in the article's Creative Commons licence and your intended use is not permitted by statutory regulation or exceeds the permitted use, you will need to obtain permission directly from the copyright holder. To view a copy of this licence, visit http://creativecommons.org/licenses/by$\mathrm{nc} / 4.0 /$.

\section{REFERENCES}

1. Limousin P, Foltynie T. Long-term outcomes of deep brain stimulation in Parkinson disease. Nat Rev Neurol. 2019;15:234-42.

2. Zibetti M, Merola A, Rizzi L, et al. Beyond nine years of continuous subthalamic nucleus deep brain stimulation in Parkinson's disease. Mov Disord. 2011;26:2327-34.

3. Gorecka-Mazur A, Furgala A, Krygowska-Wajs A, Pietraszko W, Kwinta B, Gil K. Activities of daily living and their relationship to health-related 
quality of life in patients with Parkinson disease after subthalamic nucleus deep brain stimulation. World Neurosurg. 2019;125:e552-62.

4. Espay AJ, Vaughan JE, Marras C, Fowler R, Eckman $\mathrm{MH}$. Early versus delayed bilateral subthalamic deep brain stimulation for parkinson's disease: a decision analysis. Mov Disord. 2010;25:1456-63.

5. Castrioto A, Lhommée E, Moro E, Krack P. Mood and behavioural effects of subthalamic stimulation in Parkinson's disease. Lancet Neurol. 2014;13: 287-305.

6. Okun MS, Tagliati M, Pourfar M, et al. Management of referred deep brain stimulation failures: a retrospective analysis from 2 movement disorders centers. Arch Neurol. 2005;62:1250-5.

7. Sheehy JP, Chen T, Bohl MA, Mooney MA, Mirzadeh Z, Ponce FA. Accuracy in deep brain stimulation electrode placement: a single-surgeon retrospective analysis of sterotactic error in overlapping and non-overlapping surgical cases. Stereotact Funct Neurosurg. 2019;97:37-43.

8. Pollo C, Kaelin-Lang A, Oertel MF, et al. Directional deep brain stimulation: an intraoperative doubleblind pilot study. Brain. 2014;137:2015-26.

9. Contarino MF, Bour LJ, Verhagen R, et al. Directional steering: a novel approach to deep brain stimulation. Neurology. 2014;83:1163-9.

10. Steigerwald F, Müller L, Johannes S, Matthies C, Volkmann J. Directional deep brain stimulation of the subthalamic nucleus: a pilot study using a novel neurostimulation device. Mov Disord. 2016;31: 1240-3.

11. Dembek TA, Reker P, Visser-Vandewalle V, et al. Directional DBS increases side-effect thresholds-a prospective, double-blind trial. Mov Disord. 2017;32:1380-8.

12. Rebelo P, Green AL, Aziz TZ, et al. Thalamic directional deep brain stimulation for tremor: spend less, get more. Brain Stimul. 2018;11:600-6.

13. Schnitzler AS, Mir PM, Brodsky MB, et al. Directional versus omnidirectional deep brain stimulation for Parkinson's disease: results of a prospective, blinded, multi center, single-arm crossover study [abstract]. Mov Disord. 2019;34(suppl 2).

14. Hamani C, Saint-Cyr JA, Fraser J, Kaplitt M, Lozano AM. The subthalamic nucleus in the context of movement disorders. Brain. 2004;127:4-20.

15. Hartmann-von Monakow K, Akert K, Künzle H. Projections of the precentral motor cortex and other cortical areas of the frontal lobe to the subthalamic nucleus in the monkey. Exp Brain Res. 1978;33:395-403.

16. Mathai A, Pare J, Jenkins S, Smith Y, editors. Glutamatergic inputs to the subthalamic nucleus: a quantitative analysis of the synaptic microcircuitry of vGluT1-and vGluT2-containing terminals in normal and Parkinsonian nonhuman primates. In: Xth triennial meeting of the international Basal Ganglia Society Long Branch, NJ; 2010.

17. Goldberg J, Bergman H. Computational physiology of the neural networks of the primate globus pallidus: function and dysfunction. Neuroscience. 2011;198:171-92.

18. Yelnik J. Functional anatomy of the basal ganglia. Mov Disord. 2002;17:S15-21.

19. Kim R, Nakano K, Jayaraman A, Carpenter MB. Projections of the globus pallidus and adjacent structures: an autoradiographic study in the monkey. J Comp Neurol. 1976;169:263-89.

20. Kuo JS, Carpenter MB. Organization of pallidothalamic projections in the rhesus monkey. J Comp Neurol. 1973;151:201-35.

21. Parent A, De Bellefeuille L. The pallidointralaminar and pallidonigral projections in primate as studied by retrograde doublelabeling method. Brain Res. 1983;278:111-27.

22. Parent A, Gravel S, Boucher R. The origin of forebrain afferents to the habenula in rat, cat and monkey. Brain Res Bull. 1981;6:23-38.

23. Shink E, Smith Y. Differential synaptic innervation of neurons in the internal and external segments of the globus pallidus by the GABA-and glutamatecontaining terminals in the squirrel monkey. J Comp Neurol. 1995;358:119-41.

24. Nambu A. Globus pallidus internal segment. Prog Brain Res. 2007;160:135-50.

25. Smith Y, Wichmann T, DeLong M. Synaptic innervation of neurons in the internal pallidal segment by the subthalamic nucleus and the external pallidum in monkeys. J Comp Neurol. 1994;343: 297-318.

26. Lavoie B, Parent A. Immunohistochemical study of the serotoninergic innervation of the basal ganglia in the squirrel monkey. J Comp Neurol. 1990;299: $1-16$.

27. Lavoie B, Parent A. Pedunculopontine nucleus in the squirrel monkey: projections to the basal ganglia as revealed by anterograde tract-tracing methods. J Comp Neurol. 1994;344:210-31. 
28. Lavoie B, Smith Y, Parent A. Dopaminergic innervation of the basal ganglia in the squirrel monkey as revealed by tyrosine hydroxylase immunohistochemistry. J Comp Neurol. 1989;289:36-52.

29. Lanciego J, Luquin N, Obeso J. Functional neuroanatomy of the basal ganglia. Cold Spring Harb Perspect Med. 2012;2:a009621.

30. Panov FE, Larson P, Martin A, Starr P. Deep brain stimulation for Parkinson's disease. In: Winn HR, editor. Youmans and Winn neurological surgery. 7th ed. Philadelphia: Elsevier; 2017.

31. Hamel W, Koppen JA, Alesch F, et al. Targeting of the subthalamic nucleus for deep brain stimulation: a survey among parkinson disease specialists. World Neurosurg. 2017;99:41-6.

32. Nestor KA, Jones JD, Butson CR, et al. Coordinatebased lead location does not predict Parkinson's disease deep brain stimulation outcome. PLoS One. 2014;9:e93524.

33. Bot M, Schuurman PR, Odekerken VJJ, et al. Deep brain stimulation for PD: defining the optimal location within the subthalamic nucleus. J Neurol Neurosurg Psychiatry. 2018;89:493-8.

34. Fasano A, Lozano AM, Cubo E. New neurosurgical approaches for tremor and Parkinson's disease. Curr Opin Neurol. 2017;30:435-46.

35. Sitz A, Hoevels M, Hellerbach A, et al. Determining the orientation angle of directional leads for deep brain stimulation using computed tomography and digital X-ray imaging: a phantom study. Med Phys. 2017;44:4463-73.

36. Dowsey-Limousin P. Postoperative management of Vim DBS for tremor. Mov Disord. 2002;17:S208-11.

37. Schupbach WMM, Chabardes S, Matthies C, et al. Directional leads for deep brain stimulation: opportunities and challenges. Mov Disord. 2017;32: 1371-5.

38. Anderson CJ, Anderson DN, Pulst SM, Butson CR, Dorval AD. Neural selectivity, efficiency, and dose equivalence in deep brain stimulation through pulse width tuning and segmented electrodes. bioRxiv. 2019. https://doi.org/10.1101/613133.

39. Frankenmolle AM, Wu J, Noecker AM, et al. Reversing cognitive-motor impairments in Parkinson's disease patients using a computational modelling approach to deep brain stimulation programming. Brain. 2010;133:746-61.

40. Chaturvedi A, Butson CR, Lempka SF, Cooper SE, McIntyre CC. Patient-specific models of deep brain stimulation: influence of field model complexity on neural activation predictions. Brain Stimul. 2010;3: 65-7.

41. Karl JA, Ouyang B, Verhagen Metman L. A novel dual-frequency deep brain stimulation paradigm for Parkinson's disease. Neurol Ther. 2019;8:483-9.

42. Halpern CH, Danish SF, Baltuch GH, Jaggi JL. Brain shift during deep brain stimulation surgery for Parkinson's disease. Stereotact Funct Neurosurg. 2008;86:37-43.

43. Pallavaram S, Dawant BM, Remple MS, et al. Effect of brain shift on the creation of functional atlases for deep brain stimulation surgery. Int J Comput Assist Radiol Surg. 2010;5:221-8.

44. Khan MF, Mewes K, Gross RE, Skrinjar O. Assessment of brain shift related to deep brain stimulation surgery. Stereotact Funct Neurosurg. 2008;86: 44-53.

45. Pallavaram S, Dawant BM, Li R, et al. A method to correct for brain shift when building electrophysiological atlases for deep brain stimulation (DBS) surgery. Med Image Comput Comput Assist Interv. 2009;12:557-64.

46. Matias CM, Frizon LA, Asfahan F, Uribe JD, Machado AG. Brain shift and pneumocephalus assessment during frame-based deep brain stimulation implantation with intraoperative magnetic resonance imaging. Oper Neurosurg (Hagerstown). 2018;14:668-74.

47. Dembek TA, Hoevels M, Hellerbach A, et al. Directional DBS leads show large deviations from their intended implantation orientation. Parkinsonism Relat Disord. 2019;67:117-21.

48. Morishita T, Hilliard JD, Okun MS, et al. Postoperative lead migration in deep brain stimulation surgery: incidence, risk factors, and clinical impact. PLoS One. 2017;12:e0183711.

49. van den Munckhof $\mathrm{P}$, Contarino MF, Bour LJ, Speelman JD, de Bie RM, Schuurman PR. Postoperative curving and upward displacement of deep brain stimulation electrodes caused by brain shift. Neurosurgery. 2010;67:49-53.

50. Ineichen C, Shepherd NR, Sürücü O. Understanding the effects and adverse reactions of deep brain stimulation: is it time for a paradigm shift toward a focus on heterogenous biophysical tissue properties instead of electrode design only? Front Hum Neurosci. 2018;12:468.

51. Howell B, McIntyre CC. Role of soft-tissue heterogeneity in computational models of deep brain stimulation. Brain Stimul. 2017;10:46-50. 
52. Howell B, McIntyre CC. Analyzing the tradeoff between electrical complexity and accuracy in patient-specific computational models of deep brain stimulation. J Neural Eng. 2016;13:036023.

53. Walckiers G, Fuchs B, Thiran JP, Mosig JR, Pollo C. Influence of the implanted pulse generator as reference electrode in finite element model of monopolar deep brain stimulation. J Neurosci Methods. 2010;186:90-6.

54. Yousif N, Bayford R, Bain PG, Liu X. The peri-electrode space is a significant element of the electrode-brain interface in deep brain stimulation: a computational study. Brain Res Bull. 2007;74: 361-8.

55. Howell B, Huynh B, Grill WM. Design and in vivo evaluation of more efficient and selective deep brain stimulation electrodes. J Neural Eng. 2015;12: 046030.

56. Aström M, Johansson JD, Hariz MI, Eriksson O, Wårdell K. The effect of cystic cavities on deep brain stimulation in the basal ganglia: a simulation-based study. J Neural Eng. 2006;3:132-8.
57. Yelnik J, Bardinet E, Dormont D, et al. A three-dimensional, histological and deformable atlas of the human basal ganglia. Neuroimage. 2007;34:618-38.

58. Reich MM, Horn A, Lange F, et al. Probabilistic mapping of the antidystonic effect of pallidal neurostimulation: a multicentre imaging study. Brain. 2019;142:1386-98.

59. Ten Brinke TR, Odekerken VJJ, Dijk JM, van den Munckhof P, Schuurman PR, de Bie RMA. Directional deep brain stimulation: first experiences in centers across the globe. Brain Stimul. 2018;11: 949-50.

60. Zhang S, Silburn P, Pouratian N, et al. Comparing current steering technologies for directional deep brain stimulation using a computational model that incorporates heterogeneous tissue properties. Neuromodulation. 2019. https://doi.org/10.1111/ ner.13031.

61. Wagle Shukla A, Zeilman P, Fernandez H, Bajwa JA, Mehanna R. DBS programming: an evolving approach for patients with Parkinson's disease. Parkinsons Dis. 2017;2017:8492619. 